\title{
Healthy Aging: A Case Report
}

Nazish Hussain Ali Pachani, Kiran Shoukat Ali, Armish Aziz, Laila Naushad \& Zoya Feroz Ali

Agha khan University Hospital, Nursing Department.

Corresponding Author: nazishpachani@gmail.com

\section{Abstract}

The process of aging is considered to be a weakness, disease or death. In reality, this is a myth. In West Virginia the concept of 'Healthy Aging' is developed to empower senior members of the country worldwide. This case report illustrates the application of the concept 'Healthy Aging' to an institutional setting in Karachi. This group project primarily aimed at how the client thinks, feels, communicates and respond to change in self and environment. The group planned to categorize activities into five components as physical, physiological, psychological, emotional, and spiritual domains. It builds a strong foundation for health promotion and disease prevention in older adults. Clients gain insight and group had an everlasting learning experience in geriatric care.

\section{Introduction}

Success is a basic human need for happiness and courage. Failure is often undesirable. The process of aging is considered to be a weakness, disease or death. Is this a reality or a myth? Betty Frieden quoted that, "Aging is not lost youth, but a new stage of opportunity and growth." This quote clearly depicts the both sides of societal belief. It's just a matter of thinking positively and acting creatively. The concept of 'Healthy Aging' is developed by the West Virginia Rural Healthy Aging Network, which defines it as "A development and maintenance of optimal mental, social and physical well-being" (Minnesota. Creating Healthy Communities for an Aging Population Work Group, 2006, p. 2). This concept has begun the new vision that promotes diversity, deny ageism and provide age-friendly environment for elderly to acquire independence and quality in all activities of daily routine task.

\section{Institutional Infrastructure}

At clinical setting, the group runs a project to understand and implement the core concept of elderly care. It is located in Karachi; this institution was established in 1960 and has celebrated its golden jubilee in 2010. The building has individualized rooms and a common hall in the center for all elderly people. There are total 24 rooms and 2 halls upstairs. There are 16 males and 12 females' senior citizen members. Every resident is obligated to pay a monthly fee of Rupees $1000 /$-. It is affiliated with a community welfare committee, which arrange funds and looks after the activities and necessities of elderly. There is no proper schedule of activities. All caregivers have their own specified roles in surviving the elderly client like a sister, cook, driver, watchmen and maid. These caretakers also arrange the celebrations of different events like Christmas, Easter and birthdays for elderly clients. Furthermore, all the workers serve to their utmost capacity and show their gratitude and concern towards elderly.

\section{Orientation and Ice-Breaking Activity}

At the orientation visit, the first impression that the group had was so pleasant. Plantation at the entrance, well decorated place for Jesus Christ and the warm welcome speech of sister made everybody feel good. Next, the group saw the two halls, separate for male and female, where clients were sitting isolated in the dark environment while few clients were in their small congested room. The group tried to gather everybody at a place for an introductory activity. Few came but some refused due to their physical limitation and 
disability. The group introduces themselves with their name, strength and weakness. Mostly clients were unable to share their strengths. Unlike strengths, they shared a list of weaknesses. They shared normal aging physiological and psychological changes as their weakness. Commonly were visual, hearing and memory impairment, chronic pain in joints, cataract, urinary incontinence, multiple infections, sleep deprivation, diabetes, heart related issues, depression, stress, social isolation, loneliness and suspicious thoughts. Moreover, the hall was not as ventilated as it should be. Only a single window from which limited amount of sunlight and air was passing through. The group was feeling so suffocated due to the smoke of cigarettes. The impression inside and outside the building was completely opposite. With time, the group also realized inter-sectoral conflicts among clients. Undertaking these observations, the group decided to run a project under an umbrella of 'Healthy Aging.' It was surprising that clients perceive their normal process of aging as weakness. Demystifying aging in a healthy therapeutic environment is mainly the focus of our target group. It's primarily aimed at how the client thinks, feels, communicates and respond to change in self and environment.

\section{Causal Analysis}

The group was desperate to identify the reason for the client's unsteady emotional state. With rapport building and daily spending an hour with individual clients helped to identify the underlying cause. It includes client's unhealthy practices such as drinking less or no water, skipping meals, inappropriate hand washing technique, using OTC drugs, etc. Psychologically, clients have multiple stresses like family or significant others death news or death anniversaries, misinterpreting the events, making unexpected or unrealistic goals, poor coping styles and jealousy with other active members. Moreover, clients usually belong to the lower socioeconomic background. They are being partially financed by self/family savings or by institutional funds. They perceive themselves a burden to their family.

\section{Implementation Phase}

The group planned to categorize activities into five components. These critical areas provide an opportunity to enlighten the union of mind, body and soul. First, the physical fitness domain includes relaxation technique (deep breathing exercise), stretching exercise, active and passive range of motion, and sports gala (bowling, basketball, and puzzle). These activities are essential as exercise increase oxygen concentration in the brain, thus enhances the cognition, reduce dizziness and increase enthusiasm (Meiner \& Lueckenotte, 2006).

Second, the personal hygiene and selfgrooming domain comprises bathing, hand care, foot care, massage, hair dying, mehendi and nail art. Cohen-Mansfield and Jensen in his article explained that the enhancement in personal hygiene and self-grooming provides them a therapeutic environment which increases their sense of well-being. The literature also supports that the massage therapy and hand \& foot care not only affect physically but it also affects psychologically. Hand and foot care improve blood circulation and decrease the risk of falling by maintaining stability (Pattillo, 2004). It was observed that massage therapy reduces depressive symptoms, works as a mood stabilizer, and promote sleep in them (In Sook, HeeJeong et al, 2013).

Third, the Psycho-motor and emotional domain which includes storytelling, guided imagery, laughter therapy, music therapy, and dance. The most common emotional 
disorder found in them is depression (Jaya Rani \&Vineetha, 2014). These activities promote the sense of control over the potential stress producing situation and crisis. In addition, these activities were the part of group therapy, also aid to strengthen mutual relationships. Fourth, the spirituality domain which incorporates a visit to neighboring church, specially requesting father at church for special prayers, Christmas decoration and celebration.

The literature affirms that, at old age, people are experiencing the physiological changes. At this level they need hope, love, trusting environment and meaning of life which they acquire via spirituality. Moreover, Spiritual factors also help a person to cope with pain, anxiety and other medical issues (Hertzog, 2008). Fifth, the development of cognitive skills includes collage work, card making and making a bracelet or a friendship band. This activity conveyed dual message of unity is strength and exploring the innate potential skill. These failure-free activities are selective cognitive enhancer that formed new neural connections with healthier cells and bypasses from the damage cells. (Raia, 2011) All these interventions proved to be healthier in elderly client. Sustainability in these activities is necessary to promote healthy aging concept. Upon mutual decision of the client, a nominated person is selected to initiate exercise daily during morning hours. Furthermore, the group conducted different individualized teaching sessions on proper hand washing techniques, perineal hygiene care, self-breast examination, diabetes management and stress management.

These sessions were attempting to modify client's unsafe practices and to make them protected from preventable age related complications. The teaching session was also planned for caretakers, such as for sister on the list of routine activities with scientific rationale, first aid management and brief management of fall, diabetes, and hypertension. Implementation of same routine of the activities and practices on a continuous basis can eventually help to ensure good psychological, social and physical well-being.

The group always had the unconditional support of all care providers, especially Sister and maid, in making the visit and celebration successful. Other resources are either managed by the group member or by the group's institutional body. However, certain challenges confronted into the way. For instance, there were only 16-18 clients that regularly participate in activities. This is because our activities interrupt their daily living task. They prioritize it first. One client had urinary incontinence problem, felt ashamed to participate. Some client went out for earning like giving tuitions, working at multiple shops, etc. We tried to involve them as much as possible. Secondly, implementing planned activities in dim lightening puts strain on the client's vision. Therefore, other activities were then conducted in the prayer hall with adequate lightening. Thirdly, we all were novice nurses learning essential concepts of elderly care. Therapeutic communication and cultural competency were the major concerns. With continuing support of faculty and team work enables groups to cope up with the challenge. Lastly, city emergencies were also an issue which we tried to conceal by visiting them on alternate day to have a proper conclusion and an impeccable farewell.

Conclusion

All in all, the group had an everlasting learning experience in geriatric care. All interventions were aimed at promoting healthy aging concept. It builds a strong foundation for health promotion and disease prevention in older adults. Clients gain 
insight that active, positive state of mind aid in delaying aging, saves health care cost and alleviate chronic pain. This empowerment and connectedness to the self and environment is a key to the smooth transition of ageing.

\section{References}

- Minnesota. Creating Healthy Communities for an Aging Population Work Group. (2006). Creating healthy communities for an aging population. Saint Paul, Minn.: Minnesota Dept. of Health, Office of Rural health and Primary Care, Community and Family Health Division.

- Meiner, S., \&Lueckenotte, A. G. (2006). Gerontologic nursing. St. Louis: Mosby/Elsevier.

- Cohen-Mansfield, J., \& Jensen, B. (2007). Dressing and grooming. Journal OfGerontological Nursing, 33(2), 31-39.

- Pattillo, M. (2004). Therapeutic and healing foot care: a healthy feet clinic for older

- In Sook, K., HeeJeong, Y., EunSeon, I., \&Hee Young, K. (2013). The Effects of
Aroma Foot Reflex Massage on Mood States and Brain Waves in Women Elderly with Osteoarthritis [Korean]. Korean Journal of Adult Nursing, 25(6), 644-654. doi:10.7475/kjan.2012.24.6.644

- Jaya Rani, G., \&Vineetha, J. (2014). A Study to assess the effectiveness of Laughter Therapy on Depression among Elderly People in Selected Old Age Homes at Mangalore. International Journal of Nursing Education, 6(1), 152154. doi:10.5958/j.0974-9357.6.1.031

- Hertzog, C., Kramer, A. F., Wilson, R. S., \&Lindenberger, U. (2008). Enrichment Effects on Adult Cognitive Development Can the Functional Capacity of Older Adults Be Preserved and Enhanced? Psychological Science in the Public Interest, 9(1), 1-65. doi: 10.1111/j.15396053.2009.01034.

- Raia, P. (2011). Habilitation therapy in demantia care. Age in Action-Activities in geriatric and gerontology education and research, 26(4).

- adults. Journal OfGerontological Nursing, 30(12), 25. 